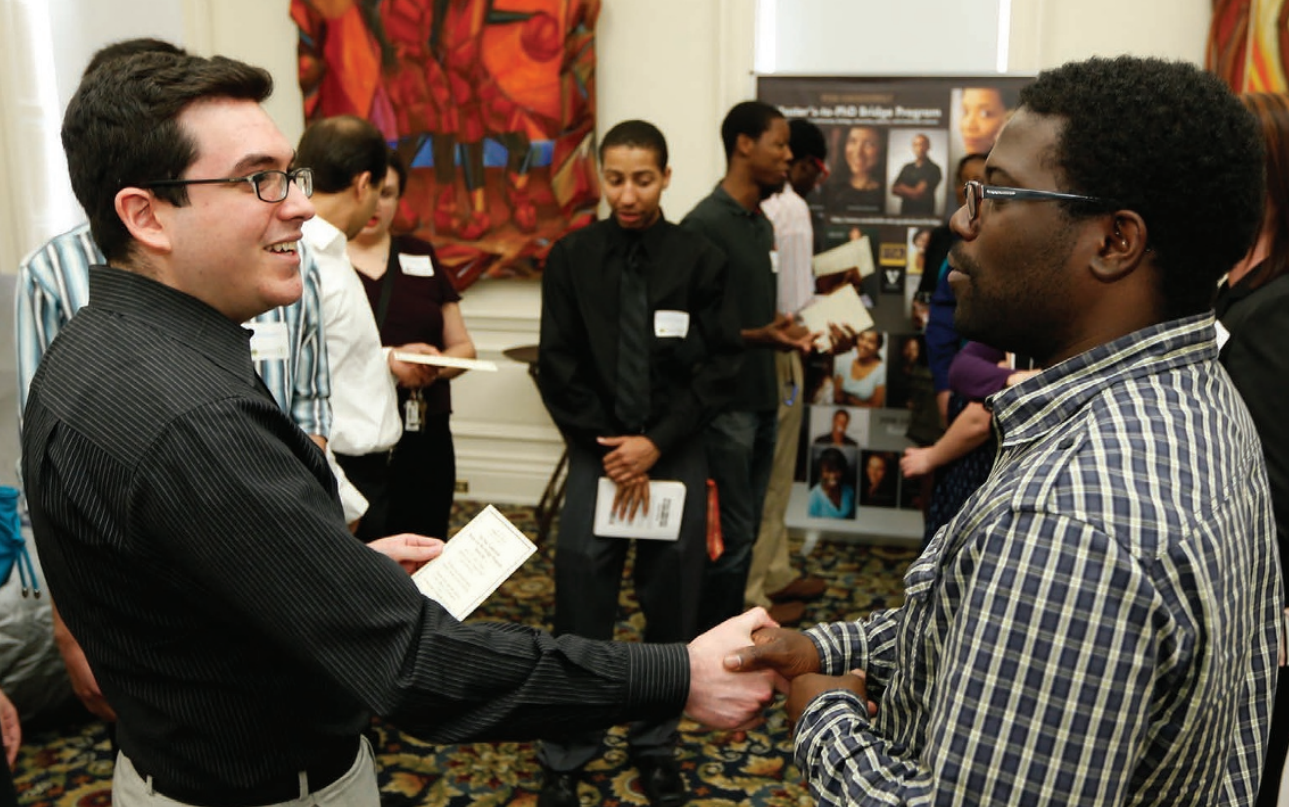

The Fisk-Vanderbilt Bridge Program links up students and mentors.

in Nashville, Tennessee, let her meet up with other students who were from groups that

are under-represented in science. In contrast to her experience as the only woman of colour in her undergraduate physics studies, Williams says that after a year in the FiskVanderbilt programme, she feels comfortable and has formed a community with fellow students. "I have been able to thrive," she says, "and see myself as a physicist."

The doctoral application process is not too early to think about ultimate career goals, says Horazdovsky. "Those can change," he says. "However, you need to make sure you will have tools or experiences to achieve your goal by the end of graduate school." For example, students who think they want to work at a mainly undergraduate institution will want significant teaching experience. Students who aim for industry will need exposure to business, companies and the jobs that PhD holders occupy. Students should also find out whether their programme of choice hosts, or at least encourages students to attend, conferences and workshops that help them to build teaching, networking and communications skills.

Many programmes include careerdevelopment components that give students real-world exposure to career tracks. These can be extremely helpful for students who are not aiming for an academic research position and can include university internships, external internships and other options.

\section{TRUE GRIT}

Students at the application stage need to stand out from the crowd to get accepted by their school of choice. David Charbonneau, director of graduate admissions for Harvard University's department of astronomy in Cambridge, Massachusetts, looks for students who have persevered in the face of obstacles. "Most of what we do in science leads to dead ends," he says. He seeks students who are passionate and hard-working, and who have demonstrated new ways of tackling problems - for example, by working through solutions to an ambitious research problem for several years. These attributes should come across through concrete examples in their letters of recommendation, he says. McLean says applicants should personalize their application statements by including a paragraph explaining which faculty members within a programme they would like to work with, and why.

If prospective $\mathrm{PhD}$ students are unsure whether graduate school is the right decision, they should take a year or two to work as a research assistant in an academic or industry lab before making the hefty commitment to doctoral studies. Taking that time is no longer viewed as a negative, says McLean, but instead shows that applicants have realistic expectations and are aware of what's ahead. Allatah Mekile was uncertain of her next steps after finishing college at East Stroudsburg University of Pennsylvania, so she moved home and took an entry-level position as a research associate at a supplier of nutritional products. There, she worked for two years on a metabolic-engineering project before applying to graduate programmes; she is now a second-year doctoral student in biochemistry, cellular and molecular biology at Johns Hopkins University in Baltimore, Maryland. She says that her experience in industry also helped her to explain in her application letter why and how certain programmes aligned with her career goals.

By eschewing the conventional path of going immediately into a doctoral programme after earning a bachelor's degree, and gambling that she'd be better prepared, Mekile showed that she was ready for graduate studies, says Bogle. "The whole point of going to graduate school is to take a bit of a risk. If you want to play it safe all the way through, then maybe graduate school - or research — isn't for you."

Kendall Powell is a freelance science journalist based in Lafayette, Colorado.

\section{GENDER BALANCE}

\section{Culture clash}

Scientific disciplines that have a 'masculine culture' tend to deter women from pursuing those fields, a study finds (S. Cheryan et al. Pyschol. Bull. http:// dx.doi.org/10.1037/bul0000052; 2016). The study analysed 1,200 publications looking at women's participation in science, technology, engineering and mathematics to learn why women are well represented in biology but not in physics, computer science and engineering. The authors found that the presence of negative stereotypes about women's abilities and the lack of female role models were major factors in deterring women. But they also found that women who feared gender bias and discrimination might be more likely to avoid certain fields. Predictors of decreased participation included a lack of pre-university experience in the field and a lack of confidence. The low numbers are also linked more to a failure to recruit female students into the fields than in retaining them, suggest the authors. Creating a more inclusive culture is the best way to boost female participation, the authors say.

\section{BIG PHARMA}

\section{UK drugs outsourced}

Biopharmaceutical companies in the United Kingdom have cut research positions in drug discovery, according to a report released by the Association of the British Pharmaceutical Industry on 17 October, entitled The Changing UK Drug Discovery Landscape. In the past decade, almost all large UK drugmakers slashed in-house research jobs in discovery, the earliest stage of drug development, when researchers usually test hundreds of thousands of compounds to find one that could move into the next stage. Overall, there has been a net loss of several hundred positions. At the same time, however, large companies have increased their investment in drug discovery through outsourcing and collaborations. A number of UK contract research organizations (CROs) reported growth in partnerships with academic drug-discovery centres. Some CROs reported more drug-discovery employees, and about one-quarter of those reported staff increases of more than $25 \%$. Yet some of the rise in CRO research jobs is also due to an increase in the number of contracts made with companies outside the United Kingdom, particularly in North America and the European Union, the report says. The UK biopharmaceutical industry employs more than 70,000 people. 